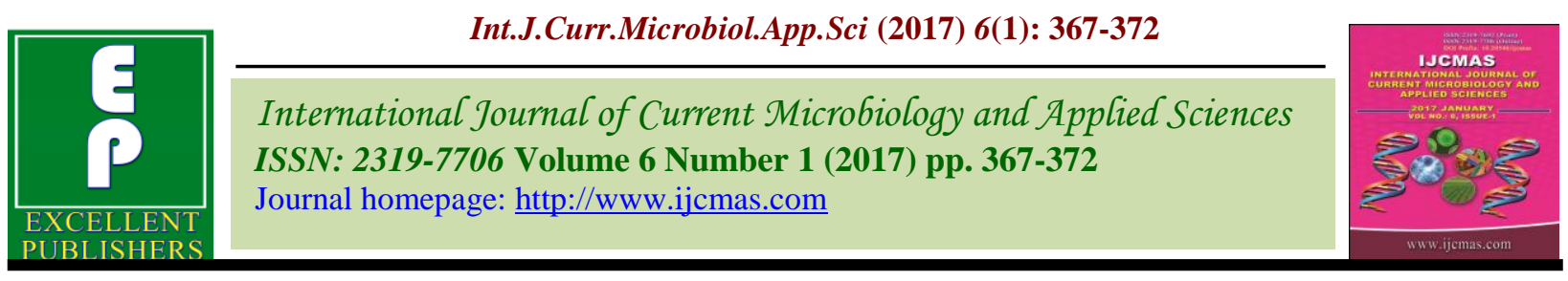

Original Research Article

http://dx.doi.org/10.20546/ijcmas.2017.601.044

\title{
Bacteriological Profile of Post Traumatic Osteomyelitis in a Tertiary Care Centre
}

\author{
Naseel Salim and J. Lancy* \\ Pulikkalakath House Chettuva, Kundaliyur PO Thrissur District Kerala, India \\ *Corresponding author:
}

\begin{tabular}{|c|c|}
\hline & A B S T R A C T \\
\hline & \multirow{7}{*}{$\begin{array}{l}\text { Osteomyelitis is an infection of the bone caused by bacteria. Osteomyelitis is one of the } \\
\text { most severe complications that can arise following trauma or surgical treatment of bone. } \\
\text { The present study was conducted in the Department of Microbiology, Government } \\
\text { Medical College, Thrissur from April } 2010 \text { to March } 2011 \text { and the objective of this study } \\
\text { was to determine the prevalence of different aerobic bacteria causing post-traumatic } \\
\text { osteomyelitis and the antibiotic susceptibility pattern of the isolates. A total of } 78 \text { samples } \\
\text { were received out ofwhich, } 53 \text { were positive by culture, while } 25 \text { were sterile. Out of the } \\
55 \text { positive samples } 7 \text { were polymicrobial and } 48 \text { had only single isolate, Staphylococcus } \\
\text { aureus was the most commonly isolated pathogen. 33(65.4\%) and } 39.4 \% \text { of } \\
\text { Staphylococcus aureus were MRSA. Other important organisms isolated included } \\
\text { Pseudomonas aeruginosa, E.coli, Klebsiellapneumonia and Proteus mirabilis. All the } \\
\text { isolates of Staphylococcus aureus were resistant to Penicillin. However, Vancomycin } \\
\text { resistance was not detected in any of the patient with MRSA. All Gram negative bacilli } \\
\text { were sensitive to Piperacillin-Tazobactam and Imipenem. Staphylococcus aureus was the } \\
\text { most commonly isolated organism. Other important organisms isolated include } \\
\text { Pseudomonas aeruginosa, E.coli, Klebsiella pneumonia and Proteus mirabilis All the } \\
\text { isolates of Staphylococcus aureus were resistant to Penicillin. However, Vancomycin } \\
\text { resistance was not detected in any of the patient with MRSA. All Gram negative bacilli } \\
\text { were sensitive to Piperacillin-Tazobactam and Imipenem. }\end{array}$} \\
\hline & \\
\hline $\begin{array}{l}\text { Osteomyelitis, } \\
\text { Staphylococcus } \\
\text { aureus, }\end{array}$ & \\
\hline $\begin{array}{l}\text { Antimicrobial } \\
\text { susceptibility. }\end{array}$ & \\
\hline Article Info & \\
\hline $\begin{array}{l}\text { Accepted: } \\
\text { 20 December } 2016 \\
\text { Available Online: } \\
\text { 10 January } 2017\end{array}$ & \\
\hline & \\
\hline
\end{tabular}

\section{Introduction}

Osteomyelitis is defined as infection in bone. The root words 'Osteon'(bones) and 'myelo' (marrow) are combined with 'itis' (inflammation) to define the clinical state in which bone is infected with microorganisms.

Osteomyelitis is usually caused by bacteria. Osteomyelitis is one of the most severe complications that can arise following trauma or after operative treatment of bone. Bones, which usually are well protected from infection, can become infected through three
Routes Blood stream, direct invasion and infections in adjacent bone or soft tissues

Bacteria may infect the bone directly through open fractures, during bone surgery, or from contaminated objects that pierce the bone. Osteomyelitis may also occur where a piece of metal has been surgically attached to a bone, as is done to repair hip or other fractures. Osteomyelitis may also result from an infection in an adjacent soft tissue. The infection spreads to the bone after several 
days or weeks. This type of spread is particularly likely to occur in older people.

This study was conducted to determine the prevalence of different bacteria in osteomyelitis and their relevance to treatment and cure.

The main objectives of this study Includes to determine the prevalence of different aerobic bacteria causing post traumatic osteomyelitis. And to describe the antibiotic susceptibility pattern of the clinical isolates.

\section{Material and Methods}

\section{Patient and study design}

Patients in all age groups and both sexes were included in the study. All patients with posttraumatic osteomyelitis admitted in the orthopaedics wards of Government Medical College, Thrissur, Kerala, India were included. The study period was one year from $1^{\text {st }}$ April 2011 to31 ${ }^{\text {st }}$ March 2012

Study design- cross-sectional study Study size -all patients in that period

\section{Collection of sample}

The specimens were collected under aseptic precautions. Specimens were (1)aspirates from bone abscesses (2)bone cuttings during surgery (3) swabs collected from sinus discharges in case of chronic osteomyelitis(4) Sinus tract aspirates. Gram staining was done and smear examined under oil immersion objective.

\section{Aerobic culture}

Bone curettings were first homogenized using a sterile pestle and mortar. Bone curettings, aspirates and swabs were inoculated on Blood agar, MacConkey agar, Chocolate Agar Brain heart infusion broth.
Readings were taken after 24 hours and 48 hours of incubation and the plates were discarded if there is no growth after 48 hours.

In case of acute osteomyelitis two blood samples were collected and inoculated in blood culture bottles containing Brain heart infusion broth and sub cultured on Blood agar and MacConkey agar on alternate days up to 7 days. Antibiotic sensitivity testing of the isolates was done on Mueller Hinton agar by Kirby Bauer method.

The identification of bacterial pathogens was done based on microscopic morphology, staining characteristics, cultural and biochemical properties using standard laboratory procedures

\section{Results and Discussion}

Out of the 78cases studied (Table1), 53 cases $(67.9 \%)$ were positive on culture while $25(32.1 \%)$ were sterile. Grams staining of all these samples showed pus cells along with organisms.

Blood culture was done for 10 patients with acute post traumatic osteomyelitis. All of them were sterile. Aspirates of these patients were also sterile.

Out of the 55 positive samples 7 were polymicrobial and 48 had only single isolate. Staphylococcus aureus was the organism most commonly isolated i.e 33(65.4\%). $13(39.39 \%)$ of S.aureus were Methicillin resistant (MRSA). Other important organisms isolated include Pseudomonas aeruginosa (20\%), E.coli (7.27\%), Klebsiella pneumoniae (3.6\%), and Proteus mirabilis (3.6\%) (Table $5)$.

All the isolates of Staphylococcus aureus were resistant to Penicillin. However, Vancomycin resistance was not detected in 
any of the patients with MRSA. All gram negative bacilli were sensitive to PiperacillinTazobactem and Imipenem. (Table 6)

In the current study the ratio of infected males to females is $6.8: 1$; this finding may be due to the more frequent exposure of males to accidents, missile injuries, trauma, and fractures. Patients with open fractures were usually young men in their teens or twenties. This may reflect the fact that young adults and adolescents who use motor vehicles are more prone to develop post traumatic osteomyelitis following accidents.

In this study, bones predominantly involved were that of lower limbs $(85.8 \%)$. The most common bone affected was tibia (41\%). This correlates with the study by Browner, Jupiter et al., (Browner, 2003). They reported that post traumatic osteomyelitis of lower extremity was more common than that of upper extremity. The tibia was the most frequent location of open fracture and accordingly was also the most frequently infected bone.

Staphylococcus aureus remains the most common pathogen isolated. Commonest gram negative isolated in the study was Pseudomonas aeruginosa followed by E. coli. This significant increase in Pseudomonas aeruginosa as a bone pathogen might be related to the increasing nosocomial infections.

Staphylococcus aureus was reported as the commonest isolate in all types of bone infections and is implicated in 50-75\% of cases of chronic osteomyelitis (Zuluaga et al., 2006; Elie et al., 2005; Shanson, 1999).

Table.1 Distribution of cases in relation to sex of the patients

\begin{tabular}{|c|cc|}
\hline Sex & \multicolumn{2}{|c|}{ No. of Cases(\%) } \\
\hline Male & 68 & $(87.17 \%)$ \\
\hline Female & 10 & $(12.82 \%)$ \\
\hline Total & $\mathbf{7 8}$ & $(\mathbf{1 0 0 \%})$ \\
\hline
\end{tabular}

Table.2 Distribution of cases according to age

\begin{tabular}{|c|c|}
\hline Age in Years & No. of cases (\%) \\
\hline$<19$ & $4(5.12 \%)$ \\
\hline $20-29$ & $14(17.9 \%)$ \\
\hline $30-39$ & $19(24.3 \%)$ \\
\hline $40-49$ & $13(16.7 \%)$ \\
\hline $50-59$ & $13(16.7 \%)$ \\
\hline $60-69$ & $9(11.5 \%)$ \\
\hline $70-79$ & $6(7.7 \%)$ \\
\hline Total & $78(100 \%)$ \\
\hline
\end{tabular}


Table.3 Distribution of bones affected by post traumatic osteomyelitis

\begin{tabular}{|c|c|}
\hline Bones involved & No. of cases (\%) \\
\hline Femur & $25(32.02 \%)$ \\
\hline Tibia & $32(41.02 \%)$ \\
\hline Fibula & $2(02.56 \%)$ \\
\hline Humerus & $2(02.56 \%)$ \\
\hline Ulna & $1(01.28 \%)$ \\
\hline Radius & $3(03.84 \%)$ \\
\hline Both bone - upper limb & $4(05.12 \%)$ \\
\hline Foot & $6(07.67 \%)$ \\
\hline others & $3(03.84 \%)$ \\
\hline Total & $\mathbf{7 8 ( 1 0 0 \% )}$ \\
\hline
\end{tabular}

Table.4 Distribution of specimens collected

\begin{tabular}{|c|c|}
\hline Type of Specimen & No. of specimens collected \\
\hline Bone curetting & 9 \\
\hline Aspirates from abscesses & 30 \\
\hline Aspirates from Sinus tract & 8 \\
\hline Sinus tract swabs & 31 \\
\hline Total & 78 \\
\hline
\end{tabular}

Table.5 Analysis of isolates

\begin{tabular}{|c|c|c|c|c|}
\hline \multirow[b]{2}{*}{ SI.NO } & \multirow[t]{2}{*}{ Organisms } & \multicolumn{2}{|c|}{ Number } & \multirow[b]{2}{*}{ Total $(\%)$} \\
\hline & & Pure & Polymicrobial & \\
\hline 1 & Staphylococcus aureus & 33 & 3 & $36(65.45 \%)$ \\
\hline 2 & $\begin{array}{l}\text { Pseudomonas } \\
\text { aeruginosa }\end{array}$ & 8 & 3 & $11(20.00 \%)$ \\
\hline 3 & E.coli & 3 & 1 & $4(07.27 \%)$ \\
\hline 4 & Klebsiella pneumoniae & 2 & 0 & $2(03.63 \%)$ \\
\hline 5 & Proteus mirabilis & 2 & 0 & $2(03.63 \%)$ \\
\hline & Total & 48 & 7 & $55(100 \%)$ \\
\hline
\end{tabular}




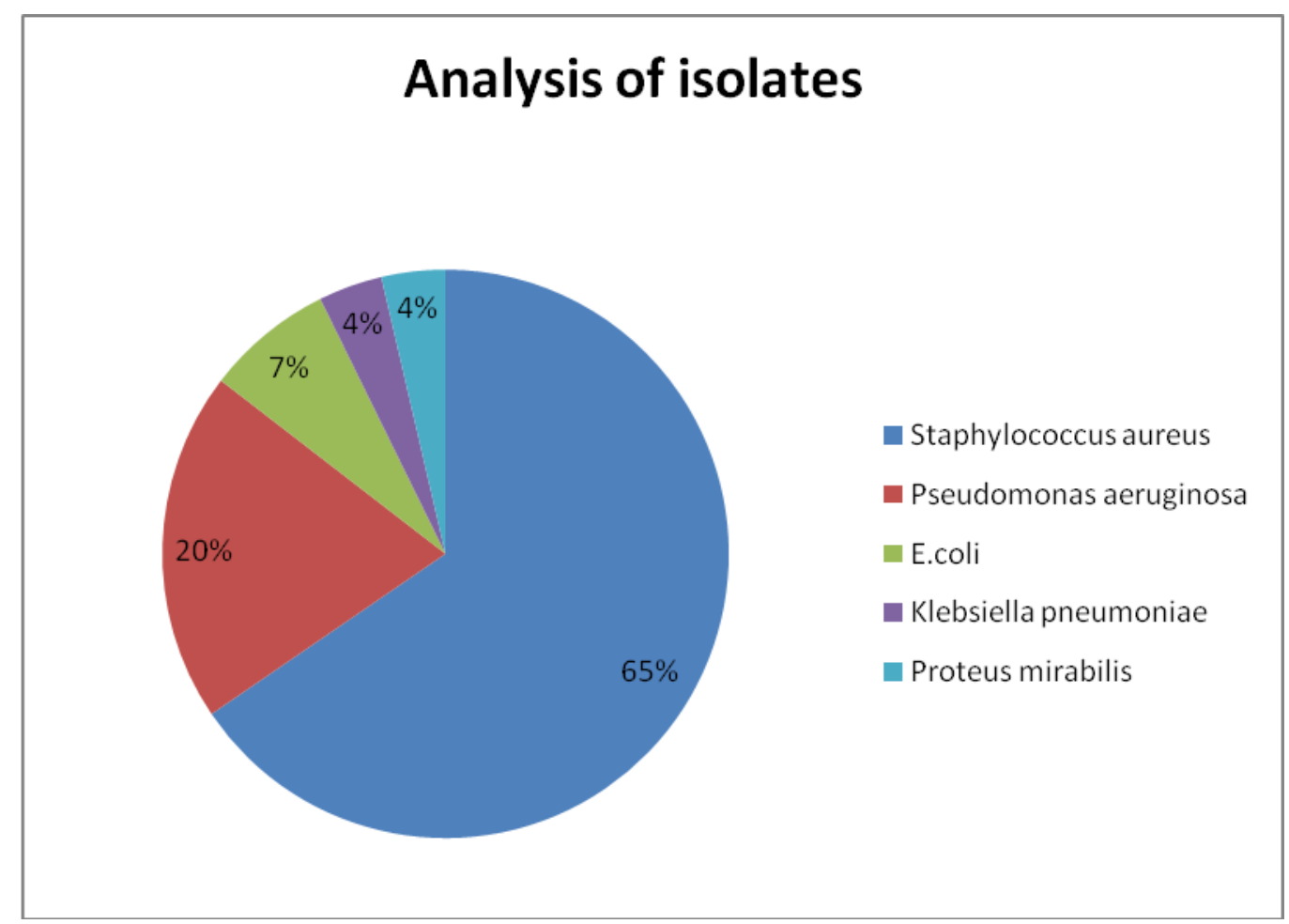

Table.6 Antibiotic susceptibility pattern of isolates (\%sensitivity)

\begin{tabular}{|c|c|c|c|c|c|c|c|c|c|c|c|c|c|c|}
\hline Organism (No.) & P & G & E & CEP & CXT & VA & A & CN & AK & CF & CE & CO & $\begin{array}{c}\text { PIPER } \\
+ \\
+ \\
\text { TAZO }\end{array}$ & IMI \\
\hline S aureus (22) & 0 & 40 & 50 & 100 & 100 & 100 & & & & & & & & \\
\hline MRSA (14) & 0 & 7.7 & 23 & 0 & 0 & 100 & & & & & & & & \\
\hline P aeruginosa (11) & & 18 & & & & & NT & NT & 72 & 27 & 45 & NT & 100 & 100 \\
\hline E. coli (4) & & 50 & & & & & 0 & 0 & 100 & 75 & 0 & 50 & 100 & 100 \\
\hline $\begin{array}{c}\text { Klebsiella } \\
\text { pneumoniae (2) }\end{array}$ & 0 & & & & & 0 & 0 & 100 & 100 & 0 & 50 & 100 & 100 \\
\hline P.mirabilis (2) & 100 & & & & & 100 & 100 & 100 & 100 & 100 & 100 & 100 & 100 \\
\hline
\end{tabular}

P-PENICILLIN,G-GENTAMICIN,CEP-CEPHALEXIN,E-ERYTHROMYCIN,CXT-CEFOXITIN, VA - VANCOMYCIN, A - AMPICILLIN,CN- CEPHALEXIN AK - AMIKACIN, CF - CIPROFLOXACIN, CE - CEFOTAXIME, CO COTRIMOXOZOLE,PIPER + TAZO-PIPERACILLIN-TAZOBACTUM,IMI-IMIPENEM.

Blood culture was done for 10 patients with acute post traumatic osteomyelitis. All of them were sterile. Aspirates of these patients were also sterile. Sample for blood cultures was collected prior to initiation of antimicrobial therapy in all patients, in whom there was suspicion of bacteraemia, fever and leukocytosis or leucopenia. Circumstances in which blood cultures are especially important include acute osteomyelitis and acute arthritis Culture of bone specimens is considered to be the gold standard for conclusive microbiological diagnosis. In the present study, only $11.5 \%$ of the specimens were bone curetting $48.7 \%$ were aspirates and $39.7 \%$ were swabs from sinus tract. There were very few bone curettings since there is some reluctance in taking bone biopsy among 
the orthopaedicians. In this study, bacterial pathogens responsible for infection were mainly monomicrobial(87.3\%). Majda Qureshi etal from Pakistan also had more monomicrobial infections in osteomyelitis (Daniel, 1997; Majda et al., 2009).

In conclusion, staphylococcus aureus was the most commonly isolated organism and $25.4 \%$ of all isolates was MRSA. Other important organisms isolated include Pseudomonas aeruginosa, E.coli, Klebsiella pneumoniae and Proteus mirabilis All the isolates of Staphylococcus aureus were resistant to Penicillin. However, Vancomycin resistance was not detected in any of the patient with MRSA. All Gram negative bacilli were sensitive to Piperacillin-Tazobactam and Imipenem.

\section{Acknowledgement}

The authors highly thankful to Dr. GIRIJA K.R, Head, Department of Microbiology Government Medical College, Thrissur and Dr. JOSE FRANCIS, Professor and HOD, Department of orthopaedics, Government Medical College, Thrissur.

\section{References}

Browner, Jupiter, Levin, Trafton. 2003. Chronic Osteomyelitis - A text book of skeletal trauma, Basic science, Management and Reconstruction, 483 488.

Daniel, P., Lew, M.D. and Francis, A. Waldvogel, M.D. 1997. Osteomyelitis. Current Concepts. New Engl. J. Med., 337(6): 428.

Elie, F., Berbari, James, et al. 2005. Osteomyelitis. Mandell, Douglas and Bennet, Principles and Practice of Infectious Diseases, Churchill Livingston, Volume $1,6^{\text {th }}$ edition; 13221332.

Majda Qureshi, Sadia Chuadry and Shala Lahore. 2009. Pakistan Bacterial etiology of bone lesions in a tertiary care hospital D:/ Biomedica, Vol.25, Jul. - Dec. 2009/Bio-22.Doc P. 180 183(WC).

Shanson, D.C. 1999. MBBS FRCPath .Bone and joint infections. Microbiology in clinical practice, 3rd edition. 305 - 308.

Sheehy, S.H., Atkins, B.A., Bejon, P., et al. 2010. The microbiology of chronic osteomyelitis: prevalence of resistance to common empirical anti-microbial regimens. J. Infect., 60(5): 338-343.

Zuluaga, A.F., Galvis, W., Saldarriaga, J.G., Aguddo, M., Salazar, B.E., Vesga, O. 2006. Etiologic diagnosis of chronic osteomyelitis; a prospective study. Arch. Intern. Med., 166: 95-100.

\section{How to cite this article:}

Naseel Salim and J. Lancy. 2017. Bacteriological Profile of Post Traumatic Osteomyelitis in a Tertiary Care Centre. Int.J.Curr.Microbiol.App.Sci. 6(1): 367-372. doi: http://dx.doi.org/10.20546/ijcmas.2017.601.044 